JOHANN WOLFGANG GOETHE-UNIVERSITÄT FRANKFURT AM MAIN

FACHBEREICH WIRTSCHAFTSWISSENSCHAFTEN

Markus C. Arnold/Robert M. Gillenkirch

Stock Options as Incentive Contracts and Dividend Policy

No. 89

April 2002

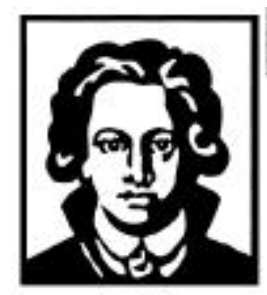

WORKING PAPER SERIES: FINANCE \& ACCOUNTING 


\title{
Stock Options as Incentive Contracts and Dividend Policy
}

\author{
Markus C. Arnold \\ Department of Economics and Business Administration \\ Clausthal University of Technology \\ markus.arnold@tu-clausthal.de \\ Robert M. Gillenkirch \\ Faculty of Economics \\ J.W.Goethe-University Frankfurt \\ gillenkirch@em.uni-frankfurt.de*
}

February, 2002

\begin{abstract}
Executive Stock Option Programs (SOPs) have become the dominant compensation instrument for top-management in recent years. The incentive effects of an SOP both with respect to corporate investment and financing decisions critically depend on the design of the SOP. A specific problem in designing SOPs concerns dividend protection. Usually, SOPs are not dividend protected, i.e. any dividend payout decreases the value of a manager's options. Empirical evidence shows that this results in a significant decrease in the level of corporate dividends and, at the same time, into an increase in share repurchases. Yet, few suggestions have been made on how to account for dividends in SOPs. This paper applies arguments from principal-agent-theory and from the theory of finance to analyze different forms of dividend protection, and to address the relevance of dividend protection in SOPs. Finally, the paper relates the theoretical analysis to empirical work on the link between share repurchases and SOPs.
\end{abstract}

JEL classification: D82, G30, G35

Keywords: Executive stock options, managerial incentives, dividends, share repurchases, dividend protection

${ }^{*}$ This paper has been presented at the EURO-Meeting 2001, section on corporate governance and contract theory, in Rotterdam. 


\section{Introduction}

Executive Stock Option Programs (SOPs) have become the largest single component of executive compensation in the US in recent years. ${ }^{1}$ Their popularity in Europe is also increasing. ${ }^{2}$ The most important incentive design features of an SOP are the exercise price, the number of options granted, the term of the options, the vesting period and trading windows, and whether the options are dividend protected. ${ }^{3}$

Stock option compensation only rewards stock-price appreciation, but does not account for dividends: The value of an option decreases with every dividend payout. Dividend protection of an SOP refers to the idea of compensating managers for dividend payouts, for example by adding accumulated dividends plus interest to the stock price upon exercise of the underlying options. In practice, firms rarely offer dividend protected SOPs. ${ }^{4}$ The literature usually attributes this lack of dividend protection in the US to the accounting treatment of dividend protected options. ${ }^{5}$

Non-dividend protected SOPs imply strict incentives for managers to cut dividends and to substitute them for a share repurchase, an alternative to cash dividends which does not adversely affect the options' value. Lambert/Lanen/Larcker (1989) find empirical evidence that managers significantly reduced the dividend level compared to the estimated level after they had been awarded stock options. Additionally, there is a striking parallel between the recent growth in SOPs and firms' use of share repurchases. Share repurchases have risen substantially in the US over the last two decades. Jolls (1998) reports ratios of repurchases to dividends of 1:12 in 1980-84, and of 1:3 in

\footnotetext{
${ }^{1}$ See Hall/Liebman (1998); Murphy (1999). Today, SOPs usually account for more than $50 \%$ of the executive compensation in large US firms. See Rappaport (1999), p. 91.

${ }^{2}$ For example, all firms in the german DAX30 have installed an SOP.

${ }^{3}$ See e.g. Carpenter (2000), Hall/Murphy (2000a;b) for analyses of the incentive effects of different exercise prices, Hall/Murphy (2000b) for the term of options and the vesting period, and for dividend protection the references in section 3 .

${ }^{4}$ Murphy (1999) reports 7 dividend protected SOPs in a sample of 618. In Germany, the fraction of dividend protected SOPs is relatively large; Winter (2000) documents dividend protection for about a third of all German SOPs.

${ }^{5}$ See e.g. Fenn/Liang (2001), Kahle (2002). According to US-GAAP, dividend protected options are considered to be variable-plan options and the cost of these options have to be recorded as an expense in the financial statement, whereas the cost of (non-dividend protected) fixed-plan options only have to be disclosed in the footnotes of the financial statement. We do not believe that the accounting treatment of SOPs provides a sufficient legitimation for the widespread omission of dividend protection. However, the accounting and tax treatment of SOPs may explain the popularity of many other design features (such as the exercise price), see e.g. Long (1992). Whether these features can be rationalized from an incentive standpoint is an open issue.
} 
1992-96. A further surge in stock repurchases can be observed for the years following this period. ${ }^{6}$ At the same time, stock price based compensation has significantly increased, mainly due to the growth in SOPs. ${ }^{7}$ The empirical observations suggest that the incentive effects of non-dividend protected SOPs with respect to corporate payout policy are significant. ${ }^{8}$

From an incentive perspective, SOPs have two main goals: Motivating managers to increase their efforts, and aligning managers' with shareholders' interests to induce "better" investment decisions. If, without agency conflicts between shareholders and managers, dividend policy were irrelevant from the shareholders' perspective, "ideal" incentive contracts would guarantee dividend irrelevance from a manager's perspective as well. On the other hand, dividend relevance from a manager's perspective implies that investment and payout decisions are related and thus, in general, dividend relevance leads to investment decisions that are not in the shareholders' best interest. ${ }^{9}$

This paper has two main purposes: First, to examine how SOPs should be designed to provide incentives for dividend decisions in the best interest of shareholders. Second, to show that neither financial investment opportunities (as an alternative to distribute cash) nor share repurchases (as an alternative to dividends) can substitute for dividend protection. Therefore, we first analyze different alternatives of dividend protection under simplifying assumptions. Applying arguments developed throughout this analysis, we subsequently discuss the role of financial investment opportunities and stock repurchases. Finally, we provide additional insights into the theoretical basis of the rapidly inreasing amount of empirical work concerning the link between dividends, stock repurchases and SOPs.

Our principal findings are these: Dividend protection, by compounding dividends with a (deterministic or stochastic) interest rate, say $r^{*}$, and adding them to the stock price when the options are exercised, "forces" the manager into a portfolio problem: The manager has to allocate the cash flow of the relevant period, which is his "budget", to two investment opportunities. He can either reinvest cash flows in the firm (a

\footnotetext{
${ }^{6}$ See Weisbenner (2000), p. 1. Empirical evidence for Germany does not yet exist because stock repurchases have been strictly limited until the "Gesetz zur Kontrolle und Transparenz im Unternehmensbereich (KonTraG)" became effective in 1998.

${ }^{7}$ From 1993 to 1998 stock market compensation nearly doubled.

${ }^{8}$ For alternative explanations of the increase in share repurchases see section 4.2.

${ }^{9}$ The same holds with respect to corporate financing decisions. See, for example, Brander/Poitevin (1992), Garvey/Mawani (1998), John/John (1993).
} 
risky investment opportunity), or he can invest them at a rate $r^{*}$ by paying out dividends. If $r^{*}$ is deterministic, the manager's problem is similar to a standard portfolio problem with one risky and one riskless asset. If $r^{*}$ is stochastic, the manager has to allocate cash flows to two risky investments. In either case the manager's solution to his portfolio problem will generally not be optimal from the shareholders' perspective, and none of the suggestions in the literature on how to design dividend protection is without drawbacks. A stochastic, firm-independent interest rate (like the return of a peer group) tends to induce better (but not first best) dividend decisions than a deterministic interest rate. First best incentives could only be provided by compounding with the stock return of the firm, if there were no information asymmetries between managers and shareholders. However, if managers have superior information, using the stock return to compound dividends will result in over- or underinvestment. Based on the analysis of alternative forms of dividend protection, it is subsequently shown that abstaining from dividend protection generally causes adverse investment incentives even if managers have alternative payout or investment opportunities. Neither stock repurchases as a payout alternative to dividends nor financial investment opportunities (as an alternative to value-reducing investments) are satisfactory substitutes for dividend protection. Finally, it is shown how the analysis helps to explain empirical results about share repurchases.

The remainder of the paper is structured as follows: In section 2 we present our model. Section 3 presents and analyzes different forms of dividend protection under the simplifying assumption that the manager can only pay out dividends or invest cash flows in real investment projects. In section 4 we expand the analysis to financial investments and stock repurchases as alternative investment opportunities and payout instruments. Section 5 concludes.

\section{The model}

To emphasize the relationship between SOPs and payout policy, we assume that the considered firm is all equity financed. The firm's cash flows belong to a given risk class with cost of capital k. The capital market is perfect and all shareholders have homogeneous expectations with respect to the firm's future cash flows from investments. Consequently, if managers acted as perfect agents of shareholders, the Miller-Modiglini 
dividend irrelevancy theorem would hold. For simplicity, we assume that, at time $\mathrm{t}=0$, the (representative) manager is granted European call options on the firm's stock that expire at time $t=2$. Let the options' exercise price $X$ be deterministic (no indexing). We do not analyze the incentive effects of the SOP on the manager's decisions during the first period but focus on his investment and payout decision at time $t=1$. At that time the manager can either invest cash flows $C F$ in the firm or distribute them to the shareholders. Accordingly, the payout $D$ is bounded to $0 \leq D \leq C F$, and the amount $C F-D$ is retained and invested internally. ${ }^{10}$

The manager may have insider-information which is strictly superior to that of the shareholders, i.e. he may have information about future cash flows of already realized or planned projects and he may anticipate projects not yet known to the shareholders. The manager has no access to capital markets: He can neither trade in shares of his firm nor in any other securities on his own account. This trading restriction is imposed to rule out that the manager's expectations enter the pricing process through his trading activities. ${ }^{11}$ Nonetheless, the manager's insider-information may be (partially) revealed to the shareholders through his payout decision: By observing the manager's payout decision (how much he disburses and whether he pays dividends or repurchases shares) the shareholders can make inferences about the manager's information and beliefs (see section 4.3 $)^{12}$ The fact that the manager's decisions convey information to the market in turn has consequences for these decisions. To simplify these complex issues, we first rule out the possibility to buy back shares and to invest cash flows into financial assets when analyzing different alternatives of dividend protection. Section 4 expands the analysis to account for these alternatives.

Therefore, in the following assume that the manager can either pay out cash flows as dividends or invest them in real investment projects of the given risk class. Let $K_{1}^{c}$ be the price (cum dividend) of the considered firm at $t=1$ before the manager announces his payout decision, and $K_{1}^{e}$ the price ex- dividend. If the manager retains

\footnotetext{
${ }^{10} D<0$ would imply a nominal capital increase (not a stock issue). Many of the following results can be easily applied to this case.

${ }^{11}$ Moreover, some restrictions on the manager's access to capital markets are necessary for incentive contracts to be effective, and it rules out the possibility that the manager values his options at market values, see e.g. Meulbroek (2001).

${ }^{12}$ The model we use is similiar to the model of Myers/Majluf (1984). They describe a setting in which the manager - acting in the interest of the "old" shareholders - has to decide about the realization of investment projects which will be financed by issuing new stock. As stock repurchases are inverse to common stock issues, many results of Myers/Majluf can be applied to our model.
} 
and internally invests cash flows $C F-D$, the shareholders estimate the corresponding projects' expected returns. Let the shareholders' estimate, which is known to the manager ex ante (i.e. before the dividend announcement), be $p$. Thus, $K_{1}^{e}$ carries more information than $K_{1}^{c}$ whenever $D<C F$. If $p=k$, the manager's dividend announcement has no price effect, and $K_{1}^{e}=K_{1}^{c}-D$. If $p \neq k$ instead, the price ex dividend is given by

$$
K_{1}^{e}=K_{1}^{c}-C F+(C F-D) \frac{1+p}{1+k}=K_{1}^{c}-D+(C F-D) \frac{p-k}{1+k}
$$

In general, there will be a difference in firm valuation between the manager and the shareholders due to the manager's superior information. Such differences in valuation are of fundamental importance for the evaluation of stock price based compensation. Differences in stock valuation result from differences in the valuation of future cash flows from existing projects as well as from the fact that the manager anticipates projects which are not yet commonly known. Valuation differences also refer to those investment opportunities at $t=1$ which the manager finances with retained cash flows.

As the manager's information is assumed to be superior, he calculates a "true" or "intrinsic" market value of the firm, and, in his eyes, the stock may be over- or underpriced. To model differences in valuation, assume that the price cum dividend at $t=2, \widetilde{K}_{2}^{c}$ results from the following process:

$$
\widetilde{K}_{2}^{c}=\left(K_{1}^{e}+\Delta\right)(1+\widetilde{r})
$$

$$
\text { with } \widetilde{r}=i+\beta(\widetilde{m}-i)+\widetilde{\varepsilon}
$$

We adopt a simple market model to explain the return of period two, $\widetilde{r}$, where $\beta$ is the firm's systematic risk, $i$ the riskless rate of return, $\widetilde{m}$ the market return and $\widetilde{\varepsilon}$ a firm-specific noise term with mean zero. The expected return is given by

$$
k \equiv E(\widetilde{r})=i+\beta[E(\widetilde{m})-i] .
$$

$\Delta$ represents the difference between the firm's intrinsic value and its market price at time $t=1$ due to the manager's superior information. (2) implies that this difference will be resolved during the second period. ${ }^{13}$ If the shareholders had the manager's

\footnotetext{
${ }^{13}$ Of course, the manager might have superior information which will not be publicly known at time $t=2$. In this case, the manager always has an incentive to communicate his information to the market if his firm is underpriced.
} 
superior information at time $t=1$, intrinsic value would equal market value and the stock return would be $\widetilde{r}$ in the second period. But with $\Delta \neq 0$, the stock return, denoted by $\widetilde{x}$, is different from $\widetilde{r}$. Though $\widetilde{r}$ is the shareholders' best guess with respect to the return in period 2 , the actual stock return is given by

$$
x=\frac{K_{2}^{c}}{K_{1}^{e}}-1=r+\frac{\Delta}{K_{1}^{e}}(1+r)
$$

Accordingly, $K_{1}^{e} \cdot(1+k)$ is the shareholders' best guess with respect to the price at $t=2$, whereas the manager's expectation is $\left(K_{1}^{e}+\Delta\right) \cdot(1+k)$. According to the potential sources for differences in valuation, we decompose $\Delta$ into

$$
\begin{aligned}
& \Delta=\bar{\Delta}+\Delta_{p} \quad \text { with } \\
& \Delta_{p}=\frac{p_{M}-p}{1+k}(C F-D)
\end{aligned}
$$

$\bar{\Delta}$ either represents the differences in valuation between manager and shareholders with respect to future cash flows of projects realized in the past, or the value of projects anticipated by the manager but not yet known to shareholders. By definition, these differences in valuation do not depend on the manager's payout decision at $t=1$. In contrast, $\Delta_{p}$ depends on the payout decision, as it represents the difference in valuation referring to the investment projects at $t=1$ that are financed with the retained cash flows $C F-D$. (7) implies that the manager values these projects' returns (which are assumed to be identical for simplicity) at $p_{M}$, whereas the shareholders estimate it to be $p$. The valuation difference $\Delta_{p}$ is one of the principal reasons why shareholders should delegate investment decisions to managers; it simultaneously rules out trivial solutions to the agency problem (e.g. a forcing contract). As both $\Delta$ and the noise term $\widetilde{\varepsilon}$ enter the formula for the stock return, $\Delta$ cannot be unambiguously inferred from $\widetilde{x}$.

The shareholders are aware of the fact that the manager has superior information, and they would share his beliefs if they had his information. Hence, from their perspective the first best-dividend policy is given by

$$
D^{f b}\left(p_{M}\right)= \begin{cases}0 & \text { for } p_{M}>k \quad \text { (retain all cash flows) } \\ \text { arbitrary } & \text { for } p_{M}=k \\ C F & \text { for } p_{M}<k \quad \text { (distribute all cash flows) }\end{cases}
$$

i.e., the first best dividend level is a step function of $p_{M}$. 
We assume that the manager is an expected utility-maximizer with utility function $U(W)$. Let the manager's wealth $\widetilde{W}$ at $t=2$ be limited to his income from the SOP. ${ }^{14}$ Without dividend protection, $\widetilde{W}$ is given by

$$
\widetilde{W}=\max \left\{\alpha \cdot\left(\widetilde{K_{2}^{c}}-X\right) ; 0\right\}=\alpha \cdot \max \left\{\widetilde{K_{2}^{c}}-X ; 0\right\}
$$

where $\alpha$ is the share in the firm's stock that corresponds to the number of options granted to the manager.

After substituting (6), (7) and (1) into (2), $\widetilde{K}_{2}^{c}$ can be written as

$$
\begin{aligned}
\widetilde{K}_{2}^{c} & =\left(K_{1}^{c}-C F+(C F-D) \frac{1+p_{M}}{1+k}+\bar{\Delta}\right)(1+\widetilde{r}) \\
& =\left(K_{1 M}^{e}+\bar{\Delta}\right)(1+\widetilde{r})
\end{aligned}
$$

where

$$
K_{1 M}^{e}=K_{1}^{c}-C F+(C F-D) \frac{1+p_{M}}{1+k}
$$

$K_{1 M}^{e}$ would represent the intrinsic (or "true") stock price ex dividend from the manager's perspective, if there were no differences in valuation except those concerning projects realized at $t=1$.

As is easily seen from (10) and (11), any dollar paid out as a dividend and not invested in projects with expected return $p_{M}$ reduces the stock price at $t=2$ by

$$
\frac{1+p_{M}}{1+k}(1+\widetilde{r}) \cdot D
$$

Thus, without dividend protection, the manager will retain and invest all cash flows as long as $p_{M}>-100 \%$.

\section{Alternative forms of dividend protection ${ }^{15}$}

\subsection{The basic principle}

Recall that, in order to simplify the analysis, we excluded share repurchases and the purchase of financial assets from the analysis so that the manager's alternatives are

\footnotetext{
${ }^{14}$ Lambert/Larcker/Verrecchia (1991) consider portfolio effects between different compensation elements as well as welfare effects resulting from non-variable compensation.

${ }^{15}$ Some results of this section are based on the unpublished master thesis of M. Arnold. See Arnold (2000), pp. 57-90.
} 
restricted to dividend payouts and investments in real projects of a given risk class. In general, dividend protection can be formalized by adding $\left(1+r^{*}\right) D$ to the stock price $\widetilde{K_{2}^{c}}$ at time $t=2$, where $r^{*}$ is a predefined interest rate, set by the shareholders. ${ }^{16}$ Equivalently, the exercise price can be reduced by the compounded dividend. ${ }^{17}$ Substituting (10) into (9), we obtain for the manager's compensation:

$$
\widetilde{W}=\alpha \cdot \max \left\{\left(K_{1 M}^{e}+\bar{\Delta}\right)(1+\widetilde{r})-\left[X-D\left(1+r^{*}\right)\right] ; 0\right\}
$$

Surprisingly, the issue of dividend protection has been largely neglected in the theoretical literature on SOPs. However, two suggestions for dividend protection have been made. Menichetti (1996) suggests compounding dividends with the firm's cost of capital, $r^{*}=k$. Wenger/Kaserer/Knoll (1999) suggest increasing the number of shares per option according to the number of additional shares a shareholder could buy from the dividend received. This form of dividend protection, which is called "Opération blanche", corresponds to using the realized stock return $\widetilde{x}$ as interest rate $r^{*}$, as will be shown in section 3.4. Both suggestions will be discussed below. ${ }^{18}$

As was shown in section 2 , any dividend payout $D$ decreases the manager's compensation by $\frac{1+p_{M}}{1+k}(1+\widetilde{r}) \cdot D$ if the SOP is not dividend protected. As can be seen from (12), inducing the first best dividend policy according to (8) would require setting $r^{*}=\widetilde{r}$ : If payed out dividends were compounded with $\widetilde{r}$, the manager's compensation at $t=2$ would be given by

$$
\widetilde{W}=\alpha \cdot \max \left\{\left(K_{1 M}^{e}+\bar{\Delta}\right)(1+\widetilde{r})-[X-D(1+\widetilde{r})] ; 0\right\}
$$

Substituting $K_{1 M}^{e}$ into (13) yields

$$
\widetilde{W}=\alpha \cdot \max \left\{\left[K_{1}^{c}-(C F-D) \frac{k-p_{M}}{1+k}+\bar{\Delta}\right](1+\widetilde{r})-X ; 0\right\} .
$$

\footnotetext{
${ }^{16}$ Alternatively, the manager can directly participate in the dividend payout, i.e. he receives $\alpha \cdot D$ when he distributes the dividend to the shareholders. There are two differences between this alternative and the dividend protection analyzed in our model. First, if dividends plus interest are added to $\widetilde{K_{2}^{c}}$, this income is at risk (as the options will not end up in the money with probability one). Second, if the dividend is directly paid out to the manager, he decides himself about $r^{*}$ whereas the shareholders determine the relevant interest rate if they opt for the form of dividend protection we consider.

${ }^{17}$ This will be the easiest way to implement dividend protection in practice. Note however, that in this case dividend protected SOPs are no longer fixed-plan options, which has consequences with respect to their accounting treatment. See footnote 5 .

${ }^{18}$ If $D<0$ "dividend protection" implies that every capital increase raises the exercice price by $D\left(1+r^{*}\right)$. This refers to the question of imputing interest charges on invested capital.
} 
Consequently, with $r^{*}=\widetilde{r}$, the first best dividend policy $D^{f b}\left(p_{M}\right)$ is a dominant strategy for the manager: If $p_{M}=k, \widetilde{W}$ is independent of $D$. If $p_{M}<k\left(p_{M}<k\right), D=C F$ $(D=0)$ maximizes $\widetilde{W}$ for any realization $r .{ }^{19}$ Moreover, if $r^{*}=\widetilde{r}$, the payout decision would be independent of $\bar{\Delta}$, eliminating any effect of valuation differences between manager and shareholders on the manager's payout decision.

As it depends on both the noise term $\varepsilon$ and the valuation difference $\Delta, r$ can neither be directly observed nor isolated from the realized stock return. Apparently, using $\widetilde{x}$ would induce optimal incentives only if $\bar{\Delta}=\Delta_{p}=0$ (and therefore $\widetilde{x}=\widetilde{r}$ ), that is only if the manager had no superior information about investment prospects in the firm. In contrast, setting $r^{*}=\widetilde{x}$ is problematic whenever $\bar{\Delta} \neq 0$ or $\Delta_{p} \neq 0$, in other words whenever the manager has superior information and the shareholders have good reason to delegate investment decisions to the manager.

\subsection{Deterministic interest rate}

First consider dividend protection with a deterministic interest rate, denoted by $r_{d}^{*}$. From the manager's perspective, the payout decision is equivalent to a portfolio problem: He has to allocate the "budget" CF among a riskless (by distributing a dividend) and a risky investment opportunity (by investing in his firm), with (expected) rates of return $r_{d}^{*}$ and $p_{M}$, respectively. The manager's decision variable is $D$, the amount invested into the "riskless asset" (or, alternatively, $C F-D$, the amount invested in the "risky asset"). This portfolio problem differs from a standard portfolio problem ${ }^{20}$ in two respects: (i) As the manager holds options, the income from dividend protection is not riskless: he will only receive compounded dividends if his options end up in the money. (ii) The manager allocates additional funds: Through his SOP a big fraction of his wage is already "invested" in the risky investment, i.e. in his firm. From (i) it follows that the manager's payout decision generally depends on how deep the manager's options are in the money and thus on the firm value at time $t=1$. (ii) complicates comparative static analyses, which will not yield the same results as the analysis of a standard problem.

\footnotetext{
${ }^{19}$ This dominance arises since we have assumed that all cash flows are of a given risk class and because we restrict the lower bound of the cash flows (of the stock return) to $0(-1)$.

${ }^{20}$ For an analysis of the corresponding standard problem see, for example, Merton (1982), pp. 602-618.
} 
In the appendix, the manager's portfolio problem is analyzed in more detail. Under quite general assumptions, the optimal dividend level that solves this portfolio problem is a smooth function of $p_{M}$ or of the difference $p_{M}-k$, respectively. The manager maximizes his expected utility by trading off the additional return from investing into the riskless asset with return $r_{d}^{*}$ against the additional risk and return from retaining cash flows and investing into the risky asset, with expected rate of return $p_{M}$. In contrast, the first best dividend level $D^{f b}\left(p_{M}\right)$ is discontinuous at $p_{M}=k$, see (8), which demonstrates the general problem of using a deterministic interest rate for dividend protection: It is not possible to design a dividend protection with a deterministic interest rate $r_{d}^{*}$ that induces a payout policy which depends as extremely on the difference between $p_{M}$ and $k$ as the first best policy (8). As a consequence, payout incentives induced by a deterministic interest rate are always suboptimal. If $r_{d}^{*}$ is low, the manager may reinvest cash flows even if $p_{M}<k$ (overinvestment). On the other hand, if $r_{d}^{*}$ is high, the manager may pay out cash flows even if $p_{M}>k$ (underinvestment). In general, $r_{d}^{*}$ has to be fixed in a way to minimize the expected welfare loss due to these suboptimal incentives. Whether a certain $r_{d}^{*}$ tends to result in over- or underinvestment of course also depends on the SOP's other design features, especially on the exercise price, and on the manager's risk preferences.

A suggestion by Menichetti (1996) which is described in more detail by Schwetzler $(1999)^{21}$ says that the deterministic interest rate $r_{d}^{*}$ should be set equal to the firm's cost of capital $k$. This implies that if the manager can realize projects with $p_{M}=k$ he has two investment opportunities with equal returns one of which is risky, the other certain. Obviously, Menichetti's proposal generally results in underinvestment, since the manager has strong incentives to pay out cash flows as long as his options are not far "underwater" (in this latter case the risk incentive from the options may overcompensate the attractiveness of dividend payouts). ${ }^{22}$

From the above arguments it additionally follows that dividend protection cannot be designed irrespective of the other SOP design features, especially the exercise price. As the probability of the options ending up in the money depends on the difference between the market price $K_{1}^{c}$ at $t=1$ and the exercise price $X$, the manager's decision

\footnotetext{
${ }^{21}$ See Menichetti (1996), p. 1690, Schwetzler (1999), p. 340.

${ }^{22}$ Therefore, Schwetzlers opinion (see Schwetzler (1999), p. 340) that setting $r_{d}^{*}=k$ ensures managerial payout decisions in the best interest of shareholders has to be questioned.
} 
to pay out also depends on this difference. The larger the difference between $K_{1}^{c}$ and $X$, the deeper in the money the manager's options are, and the more the manager's risk aversion affects his payout decision. On the other hand, the smaller the probability of the manager's options ending up in the money, the larger the risk incentive from the manager's options, which again affects his payout decisions. At an optimum, the interest rate for dividend protection thus has to be state contigent. Specifically, for a given exercise price, the optimal $r_{d}^{*}$ tends to be the smaller, the larger $K_{1}^{c}$ is. A second reason for $r_{d}^{*}$ to be state contingent is wealth effects.

\subsection{Stochastic, firm-independent interest rate}

Next consider a stochastic, firm-independent interest rate, such as an index return, or the return of a peer group, and denote it by $\widetilde{r}_{I}^{*}$. We will turn to the stock return as a firm-dependent stochastic interest rate in the next section.

Assume for example that the return of a peer group $\widetilde{r}_{I}$ is available which has the same $\beta$ as the firm but is not exposed to the firm-specific risk. As $\left.E\left(\widetilde{r}_{I}\right)=k\right)$, using this return for dividend protection implies that the manager, faced with internal investment opportunities with expected return $p_{M}=k$, can avoid firm specific risk without any loss in expected return by paying out dividends instead of investing cash flows in the firm. Consequently, the expected return on dividend payouts should generally be smaller than $\mathrm{k}$. Therefore, define the interest rate used for dividend protection as:

$$
\widetilde{r}_{I}^{*}=i+\beta(\widetilde{m}-i)-\lambda=\widetilde{r}_{I}-\lambda
$$

i.e. as the return of the peer group reduced by $\lambda$. With this interest rate, the manager's compensation is

$$
\begin{aligned}
\widetilde{W} & =\alpha \cdot \max \left\{\left(K_{1 M}^{e}+\bar{\Delta}\right)(1+\widetilde{r})-\left[X-D\left(1+\widetilde{r}_{I}^{*}\right)\right] ; 0\right\} \\
& =\alpha \cdot \max \left\{\left(K_{1 M}^{e}+\bar{\Delta}\right)(1+\widetilde{r})-[X-D(1+\widetilde{r})]-D(\widetilde{\varepsilon}-\lambda) ; 0\right\}
\end{aligned}
$$

The reduction in the expected return is similar to choosing $r_{d}^{*}<k$ in the case of a deterministic interest rate. This can be generalized: If the shareholders use a stochastic interest rate which is not perfectly correlated with $\widetilde{r}$, its expected value generally must not be equal to the cost of capital $k$. As with a deterministic interest rate, the manager faces a portfolio problem, now referring to the allocation of a given budget 
$(C F)$ to two risky investment opportunities. In the appendix, we analyze this portfolio problem in more detail. There, we also address the question of whether a stochastic interest rate $\widetilde{r}_{I}^{*}$ performs better than a deterministic rate $r_{d}^{*}$. It is shown that, under quite general assumptions, the use of $\widetilde{r}_{I}^{*}$ does indeed induce superior payout decisions. Specifically, with $\widetilde{r}_{I}^{*}$ instead of $r_{d}^{*}$ being used for dividend protection, the dividend level that maximizes the manager's expected utility is more sensitive to $p_{M}$, and so the manager's choice of $D$ more strongly depends on the difference $p_{M}-k$, resulting in a better approximation of the first best dividend policy given by (8). In general, $\widetilde{r}_{I}^{*}$ will perform better, the closer it is correlated with $\widetilde{r}$. The intuition behind the result is simple: the stronger $\widetilde{r}_{I}^{*}$ and $\widetilde{r}$ are correlated, the less dependent the manager's risk premium is on his choice of $D$, and the more his decision will depend on the difference in the expected returns of his investment opportunities, i.e. retaining and internally investing cash flows or paying dividends, respectively.

Though using $\widetilde{r}_{I}^{*}$ instead of a deterministic rate tends to improve incentives, still no optimal solution can be achieved, as any firm-independent return cannot account for the firm specific risks $\widetilde{\varepsilon}$. The only way to account for these risks is to use the stock return of the firm as the interest rate for dividend protection, which leads to the following section.

\subsection{The stock return}

Wenger/Kaserer/Knoll (1999) propose the so-called "Opération blanche" for dividend protection. According to the "Opération blanche", the number of shares per option is increased according to the number of additional shares a shareholder could buy from the dividend received. ${ }^{23}$

If a shareholder holds a fraction $z$ of the firm's equity, he receives a dividend payment of $z \cdot D$. With a stock price ex dividend of $K_{1}^{e}$, the number of additional shares he can buy with $z \cdot D$ is given by $z \cdot \frac{D}{K_{1}^{e}}$. If the manager's options correspond to a fraction $\alpha$ of the firm's equity, the "Opération Blanche" gives the manager additional $\alpha \cdot \frac{D}{K_{1}^{e}}$ options for a payout $D$. For the value of the underlying shares at $t=2(\mathrm{cum}$

\footnotetext{
${ }^{23}$ See Wenger/Kaserer/Knoll (1999), p. 488. Winter's description of how to account for dividends in SOPs is equivalent to the "Opération blanche". See Winter (2000), p. 181.
} 
dividend) we obtain:

$$
\alpha\left(1+\frac{D}{K_{1}^{e}}\right) \cdot \widetilde{K}_{2}^{c}=\alpha\left(\widetilde{K}_{2}^{c}+D \cdot \frac{\widetilde{K}_{2}^{c}}{K_{1}^{e}}\right)=\alpha\left[\widetilde{K}_{2}^{c}+D \cdot(1+\widetilde{x})\right]
$$

From (16) we see that the "Opération Blanche" is equivalent to adding $D \cdot(1+\widetilde{x})$ to the stock price at $t=2$, i.e. equivalent to compounding dividends with the realized stock return of the second period.

As the manager can either pay out dividends or invest internally, with dividend protection based $r^{*}=\widetilde{x}$ the manager has two investment opportunities with perfectly correlated returns. Apparently, the " Opération Blanche"" would be the optimal solution to our problem if $\widetilde{x}=\widetilde{r}$, that is if there was no difference in valuation between manager and shareholders $(\Delta=0)$. As was noted in section 2 , differences in valuation result from the manager's superior information both with respect to projects realizable at $t=1\left(\Delta_{p}\right)$ and to future cash flows of both already realized projects and projects anticipated by the manager but not yet known to the shareholders $(\bar{\Delta})$. In the first case the valuation difference depends on the payout decision, whereas in the second it does not. Recall that differences between the market price and the intrinsic value of the firm at $t=1\left(\bar{\Delta}\right.$ and/or $\left.\Delta_{p}\right)$, are assumed to be temporary and hence will be resolved at the end of period 2 .

First, ignore differences in the valuation of projects realizable at $t=1$, i.e. assume $\Delta_{p}=0, p_{M}=p$, and consider the case $\bar{\Delta}>0$ : From the manager's perspective, the firm is underpriced at time $t=1$ and the manager expects a stock return $E(\widetilde{x})>k$ for period 2. Now, as the two alternatives have perfectly correlated returns, paying out dividends will dominate internal investments with expected return $p_{M} \leq k$, and the "Opération Blanche" results in underinvestment, as the manager may pay out dividends even if $p_{M}>k$. On the other hand, if the firm is overpriced $(\bar{\Delta}<0$ and $E(\widetilde{x})<k)$, the manager tends to overinvest, since even a project with expected return $p_{M}$ slightly lower than $\mathrm{k}$ will dominate a dividend payout.

The "Opération blanche" will result in over- or underinvestment even if differences in valuation are exclusively related to those projects that are to be financed with retained cash flows (recall that without such differences, there is no reason for delegating the investment and payout decisions at $t=1$ to the manager). To see this, assume $\bar{\Delta}=0$, but $\Delta_{p} \neq 0$. Inserting (10) and $r^{*}=\widetilde{x}$ into (9), we obtain for the manager's 
wage

$$
\widetilde{W}=\alpha \cdot \max \left\{\left[K_{1}^{c}-\frac{C F-D}{1+k}\left[k-p_{M}-\frac{D}{K_{1}^{c}}\left(p_{M}-p\right)\right]\right] \cdot(1+\widetilde{r})-X ; 0\right\}
$$

According to (17), the payout decision has two effects on the manager's compensation, represented by the terms $-\frac{C F-D}{1+k}\left(k-p_{M}\right)$ and $\frac{C F-D}{1+k} \cdot \frac{D}{K_{1}^{c}}\left(p_{M}-p\right)$, respectively. The first effect reflects the profitability of the real investment projects and directs the manager towards the first best dividend policy: If $p_{M}=p$ (and so $\frac{C F-D}{1+k} \cdot \frac{D}{K_{1}^{c}}\left(p_{M}-p\right)=0$ ), $D^{f b}\left(p_{M}\right)$ would be a dominant strategy for the manager. The second effect applies only if $0<D<C F$ : If he distributes all cash flows so that $D=C F$, there is by definition no information effect on the stock price. If he retains all cash flows so that $D=0$, the interest rate for dividend protection is irrelevant. The second effect reflects the difference in the valuation of projects to be realized at $t=1$ between shareholders and manager: If the manager retains cash flows (but not all, i.e. $0<D<C F$ ) and invests them internally, the expected stock return and thus the return on distributed cash flows for the manager, is

$$
E(\widetilde{x})=k+\frac{(C F-D)\left(p_{M}-p\right)}{K_{1}^{e}}
$$

which differs from $\mathrm{k}$ whenever $p_{M} \neq p$. As the second effect is negative if $p_{M}<p$, the manager can eliminate it by setting $D=0$ or $D=C F$. As either case will always maximize the first effect, there is no conflict of interest between manager and shareholders whenever $p_{M}<p$, that is whenever shareholders overvalue the projects to be financed. Things change if $p_{M}>p$ : In this case, there is an interior maximum for the second effect, and so the manager will underinvest if $p_{M}>k$ (the manager suboptimally pays out some dividend) and will overinvest if $p_{M}<k$ (he suboptimally retains some cash flows). The more "pessimistic" the shareholders, the more the manager's dividend policy will deviate from first best.

If the shareholders cannot distinguish between different sources of misvaluations $\left(\bar{\Delta}\right.$ and $\Delta_{p}$ ) the inference from the manager's payout decision on his expectations is very limited. ${ }^{24}$ As a result, even if we take into account the informative effect of the manager's decisions, the desribed adverse investment incentives tend to prevail.

\footnotetext{
${ }^{24}$ For example, the shareholders cannot conclude from a complete payout that the firm is underpriced from the manager's perspective $(\bar{\Delta}>0)$ as they do not know whether there are any valuable projects at all.
} 
Summing up, dividend protection with the "Opération blanche" tends to be problematic if the shareholders have good reason to believe that the manager values the firm differently. The "Opération blanche" may even be problematic if the difference in valuation only concerns projects to be financed with the retained cash flows at $t=1$.

\section{Dividend protection, financial investment opportunities and stock repurchases}

\subsection{Financial investment opportunities}

A straightforward and simple argument questioning the need for dividend protection is as follows: If capital markets are perfect, which we assumed, shareholders can simply allow managers to purchase financial assets, e.g. invest retained cash flows at the riskless interest rate. Now, retaining cash flows will not imply value-reducing investment decisions made by the manager if he prefers financial to real investments if (and only if) $p_{M}<k$. Financial investment opportunities remain largely unconsidered in both the theoretical and the empirical literature on SOPs. ${ }^{25}$

Assume that the manager can purchase a riskless asset with return $i$. Further assume that he is not restricted with respect to this investment, i.e. that he is allowed to invest all cash flows CF into the riskless asset. From the manager's perspective, this financial investment opportunity is equivalent to a dividend protection of the SOP with deterministic interest rate $r_{d}^{*}=i$. Obviously, a (explicit) dividend protection is now at best irrelevant. The same holds with respect to risky financial investments in the firm and dividend protection with a stochastic interest rate. However, the analyses in sections 3.2 and 3.3 have shown that it is questionable whether optimal interest rates for dividend protection, whether deterministic or stochastic, will equal the returns of bonds or risky assets traded on capital markets. This becomes apparent especially when we compare investments in risky financial assets with a dividend protection based on a stochastic interest rate. As was argued, the optimal rate $\widetilde{r}_{I}^{*}$ carries a negative premium $\lambda$ on its expected return to account for the firm-specific risks not inherent in the index (benchmark) portfolio. In general, a risky asset with the desired characteristics will not be available on an arbitrage-free market. Additionally, the riskless interest rate

\footnotetext{
${ }^{25}$ Neus (1996) analyzes linear incentive contracts and shows that financial investment opportunities adversely affect the manager's motivation.
} 
available at the market, will only by chance be equal to the deterministic interest rate that is optimal for dividend protection.

Consequently, financial investment opportunities represent an implicit but generally suboptimal substitute for dividend protection. For SOPs to induce first best dividend decisions, other design features, such as the exercice price, will then have to be designed (if possible) such that the adverse incentives from financial investment opportunities will be compensated. The degree of freedom lost hereby will have a negative impact on other incentive effects. Hence, from a theoretical perspective, it is generally advantageous for the shareholders to (implicitly or explicitly) restrict the manager's corporate financial investment opportunities and simultaneously include dividend protection into the SOP.

\subsection{SOPs and share repurchases}

So far, we have not taken into account share repurchases. Share repurchases are an alternative way to distribute cash to shareholders which, in contrast to a dividend payout, do not adversely affect the value of the manager's options. So, if the manager can choose between paying out cash in form of dividends or a share repurchase, he will strictly prefer the repurchase. As a consequence, we expect managers to systematically substitute share repurchases for dividends when compensated with non-dividend protected SOPs. Kahle (2002) refers to this reasoning as the substitution hypothesis. The substitution hypothesis provides an explanation for the striking parallel between the growing importance of SOPs as compensation instruments and the change in corporate payout policy from dividends to repurchases in recent years. Of course, there are other explanations for this link. A straightforward explanation is the "funding hypothesis" (Kahle, 2002, pp. 240-241): Whenever managers or other employees exercise options, the firm as the option writer has to provide the necessary (underlying) shares, and so the considered manager may repurchase shares for this reason. ${ }^{26}$

The empirical link between SOPs and share repurchases is well documented. ${ }^{27}$ The empirical evidence supports both the funding and the substitution hypothesis: Ac-

\footnotetext{
${ }^{26}$ Alternatively, firms can issue new stock. Share repurchases may be preferred because they do not dilute EPS, which is still frequently used for firm valuation in practice. See Kahle (2002), pp. 240-241, Weisbenner (2000), pp. 6-8. As Kahle (p. 240) points out, the economic rationale for the funding hypothesis is "unclear".

${ }^{27}$ See Fenn/Liang (2001), Jolls (1998), Weisbenner (2000), Klassen/Sivakumar (2001), Kahle (2002).
} 
cording to Liang/Sharpe (1999) and Weisbenner (2000), increases in stock repurchases are significantly positively related to the number of SOPs for non-executive employees. Assuming that these employees have little influence on corporate payout decisions, this supports the funding hypothesis. Additionally, Weisbenner (2000) observes that executive SOPs are related with both stock repurchases and retained earnings, which confirms the substitution hypothesis as well as the findings in Lambert/Lanen/Larcker (1989). The results in Fenn/Liang (2001) and Jolls (1998) are also consistent with the substitution hypothesis. Kahle (2002) explicitly controls for the two hypothesis by differentiating between executive and non-executive SOPs. She finds evidence confirming both hypotheses.

Accounting for share repurchases, like financial investment opportunities, leads to a simple argument questioning the need for dividend protection in SOPs: shareholders can simply tell managers to buy back stock as a substitute for dividend protection in the SOP. In fact, if shares are repurchased at market prices, the repurchase yields return $\widetilde{x}$ and thus is equivalent to a (explicit) dividend protection according to the "Opération Blanche". The "Opération Blanche" has been analyzed in section 3.4. There, it was shown that it results in adverse investment incentives whenever the manager has information which is superior to (more generally: which is not identical to) that of the shareholders. Consequently, share repurchases induce suboptimal dividend and payout decisions whenever there is asymmetric information between manager and shareholders. Share repurchases are in the shareholders' best interest only if they prefer the "Opération Blanche" to any other form of dividend protection. If not, they may prefer to restrict the manager's payout alternatives and establish a (explicit) dividend protection in the SOP.

The argument that share repurchases can substitute for dividend protection becomes even more questionable if one accounts for the fundamental difference between dividends and share repurchases. Though they are equivalent for the manager, they are not equivalent for shareholders: Dividend distributions are "pro rata", i.e. every shareholder receives a fraction of $D$ according to his share in the firm's equity. Accordingly, a share repurchase is only equivalent to dividends if all shareholders participate pro rata in the repurchase. If otherwise they do not participate pro rata in the buyback, the repurchase, unlike dividends, will result in a reallocation of wealth among shareholders whenever the firm is over- or undervalued. The omission of dividend pro- 
tection "forces" the manager into a repurchase if he prefers distributing cash flows to investing them internally. As a result, it can be in the interest of the shareholders not to discriminate dividends but to install an explicit dividend protection to make dividends a more attractive payout alternative for the manager.

\subsection{Revelation of information through payout decisions}

In section 3.4, analyzing the "Opération Blanche", we have noted that the manager's payout decision does not reveal much of his superior information to the market, if his alternatives are restricted to distributing dividends or retaining and internally investing cash flows. As for the manager, a share repurchase is equivalent to dividend protection with the "Opération Blanche", the same holds for the case of a non-dividend protected $\mathrm{SOP}$ and the manager's choice between a share repurchase and investments in real projects. Note that this implies that the "substitution" hypothesis described in the preceding section does not predict any signalling effects of share repurchases.

The situation changes if we additionally consider financial investment opportunities and/or dividend protection with a firm-independent interest rate. Now, the manager has an alternative which the shareholders correctly value. As a consequence, his decision in general will convey information to the market. For example, assume that at time $t=1$, the manager can either internally invest retained cash flows, or purchase financial assets, or pay out dividends, and that his SOP is dividend protected according to the Opération blanche. Note that, from the manager's perspective, this is equivalent to assuming that the SOP is not dividend protected, but that the manager may repurchase shares. Irrespective of real investment opportunities, the manager will tend to retain cash flows (and purchase financial assets) if the firm is overpriced, i.e. if $\Delta<0$, since $\Delta<0$ implies a relatively low stock return in period 2 which makes the dividend payment under "Opération Blanche" (the repurchase) less attractive. Hence, in this case, retaining cash flows and purchasing financial assets on average signals to the market that the firm is overpriced. On the other hand, a share repurchase, when shareholders know that the manager could alternatively retain cash flows and purchase financial assets, on average signals underpricing. However, the corresponding price reaction is adversely affected by the fact the shareholders generally cannot attribute share repurchases to the manager preferring a repurchase to financial investments. For ex- 
ample, financial investments may be restricted, or the manager may repurchase shares for other reasons such as the funding motive described above. ${ }^{28}$ Of course, the market reactions to a repurchase, if anticipated by the manager, in turn affect his strategy. A thorough analysis of the information effects of a manager's payout and investment decisions when he is compensated with stock options (whether dividend protected or not) is beyond the scope of this paper.

Market reactions to share repurchases have been extensively analyzed in the empirical literature. The announcement of share repurchases are "good" news and cause significant stock price increases. ${ }^{29}$ Recent studies also refer to the role of SOPs. ${ }^{30}$

With respect to the role of SOPs, market reactions to a share repurchase should be expected to be more significant, in relation to how precisely shareholders can infer managerial motives from the decision to repurchase shares. This inference tends to be less precise particularly when the manager's alternatives (both with respect to investment and to payout decisions) are restricted, and other motives for a repurchase are probable, such as the funding motive. This indicates that empirical studies of share repurchases (i) should account for SOPs, (ii) should, like Kahle (2002), try to distinguish between managerial motives to increase option values and simple funding motives for employee SOPs, and (iii) should try to account for financial investments.

Recent empirical findings not only point out the link between SOPs and share repurchases. They can also be seen as evidence for the need for dividend protection in SOPs, as long as it is accepted that share repurchases, driven by managers' incentives to avoid depreciation of their option values, will generally not be in the shareholders' best interest.

\section{Conclusion}

Dividend protection of SOPs is largely ignored in theory and practice regardless of the fact that abstaining from dividend protection causes adverse investment incentives. Neither stock repurchases as a payout alternative nor corporate financial investment

\footnotetext{
${ }^{28}$ In turn, a dividend protection with a firm-independent interest rate may improve the shareholders' ability to infer the manager's information from his payout decision.

${ }^{29}$ See e.g. Dann (1981); Vermaelen (1981, 1984); Comment/Jarrell (1991); Ikenberry/Lakonishok/Vermaelen (1995); Otchere/Ross (2001).

${ }^{30}$ See Klassen/Sivakumar (2001); Kahle (2002).
} 
opportunities can completely eliminate the need for dividend protection.

In the literature, few suggestions have been made on how to design dividend protection. Two of them were discussed in the paper. The suggestion to compound dividends with the cost of capital $\mathrm{k}$ should generally be rejected. The second suggestion, the so-called "Opération Blanche", would represent an ideal solution only if there were no informational asymmetries between manager and shareholders. Adverse investment incentives for the more realistic case of informational asymmetries are difficult to predict. Then, dividend protection based on a firm-independent stochastic interest rate, for example linked to the performance of a peer group, may be preferred by the shareholders.

Actually, the theoretical analysis of the relationship between SOPs and payout decision reflects a more fundamental problem: Incentive contracts designed to increase managerial motivation and to induce "good" investment decisions should be independent of corporate financing decisions if it is expected that such decisions have relatively small influence on firm value. However, it is an open question whether it is possible to design such incentive contracts. ${ }^{31}$

Finally, the analysis of our paper shows that the effect of different SOP design features, such as indexing options or dividend protection, have to be analyzed simultaneously in order to account for their impacts on investment policy as well as on financing decisions. This would require an integrated analysis of the incentive effects of SOPs with respect to different agency-problems, which cannot be found in the literature up to now.

\footnotetext{
${ }^{31}$ For a discussion of this question referring to equity issues, see Dybvig/Zender (1991) and Persons (1994).
} 


\section{Appendix: The manager's portfolio problem}

\section{Deterministic interest rate $\mathbf{r}_{\mathbf{d}}^{*}$}

We start with the manager's expected utility in case of a dividend protection with the deterministic interest rate $r_{d}^{*}$. Normalizing $U(W)$ to $U(0)=0$, the manager's expected utility is given by

$$
\begin{aligned}
& E[U(\widetilde{W})]=\int_{r_{X}} U\left(\alpha\left\{\left(K_{1 M}^{e}+\bar{\Delta}\right) \cdot(1+r)-\left[X-D\left(1+r_{d}^{*}\right)\right]\right\}\right) f(r) d r \\
& \text { with } r_{X} \equiv \frac{X-D\left(1+r_{d}^{*}\right)-\left(K_{1 M}^{e}+\bar{\Delta}\right)}{K_{1 M}^{e}+\bar{\Delta}}
\end{aligned}
$$

Denote the dividend level that maximizes (A-1) by $D^{\text {opt }}$. Under quite general conditions, $D^{o p t}$ is a smooth function of $p_{M}$. This implies that the manager's dividend decisions will deviate from the first best policy, which is a step function with step at $p_{M}=k$. Differentiating $(\mathrm{A}-1)$ with respect to $D$ gives:

$$
\frac{\partial E[U(\widetilde{W})]}{\partial D}=\alpha \cdot \int_{r_{X}} U^{\prime}(W) \cdot\left[1+r_{d}^{*}-\frac{1+p_{M}}{1+k}(1+r)\right] \cdot f(r) d r
$$

Assume that the second-derivative $\partial^{2} E[U(\widetilde{W})] / \partial D^{2}$ is negative in $[0, C F]$. Then, $E[U(\widetilde{W})]$ either has an interior maximum $\left(0<D^{o p t}<C F\right)$, or a boundary maximum at $D^{o p t}=C F$ (the manager would prefer to pay out even more than $\mathrm{CF}$ ) or at $D^{\text {opt }}=0$ (the manager would prefer to invest internally even more than CF). Obviously, in either case, the manager's dividend decision generally is suboptimal from the shareholders' perspective. Define the conditional density $\widehat{f}(r)=\frac{f(r)}{1-F\left(r_{X}\right)}\left(\right.$ with $\left.\int_{r_{X}} \widehat{f}(r) d r=1\right)$ and insert $\widehat{f}(r)$ into (A-2) to receive:

$$
\frac{\partial E[U(\widetilde{W})]}{\partial D}=\alpha \cdot\left[1-F\left(r_{X}\right)\right] \hat{E}\left\{U^{\prime}(\widetilde{W}) \cdot\left[1+r_{d}^{*}-\frac{1+p_{M}}{1+k}(1+\widetilde{r})\right]\right\}
$$

where $\hat{E}(\cdot)=E\left(\cdot \mid \widetilde{r} \geq r_{X}\right)$ represents the operator for conditional expectations (such that, in $\hat{E}(\cdot)$, realizations of $\widetilde{r}$ are weighted with $\widehat{f}(r))$. An interior maximum satisfies

$$
\hat{E}\left\{U^{\prime}(\widetilde{W}) \cdot\left[1+r_{d}^{*}-\frac{1+p_{M}}{1+k}(1+\widetilde{r})\right]\right\}=0
$$

This first order condition corresponds to the first order condition for a standard portfolio with one riskless and one risky asset known from portfolio theory. ${ }^{32}(\mathrm{~A}-3)$ allows

\footnotetext{
${ }^{32}$ In fact, for $1-F\left(r_{X}\right) \approx 1$ and $p_{M}=k,(\mathrm{~A}-3)$ simplifies to the standard condition $E\left\{U^{\prime}(W) \cdot\left(\widetilde{r}-r_{d}^{*}\right)\right\}=0$. See Merton (1982), p. 604 .
} 
comparative static analyses of the manager's dividend decision. Though, these analysis are complicated by the fact that the manager (i) holds a nonlinear claim on his portfolio, and that he (ii) already has "invested" a large part of his wealth in the risky asset. Thus, consider first the simple case of $p_{M}=k$ and $r_{X} \approx 0$, i.e. assume that internal investments yield mean returns equal to $\mathrm{k}$ and that the options end up in the money with probability 1 . Then, (A-3) can be rewritten as follows: ${ }^{33}$

$$
E\left\{U^{\prime}(\widetilde{W}) \cdot\left(r_{d}^{*}-\widetilde{r}\right)\right\}=E\left[U^{\prime}(\widetilde{W})\right] \cdot\left(r_{d}^{*}-k\right)-\operatorname{Cov}\left[U^{\prime}(\widetilde{W}), \widetilde{r}\right]=0
$$

$\operatorname{Cov}\left[U^{\prime}(\widetilde{W}) \widetilde{r}\right]<0$ due to the manager's risk aversion. Therefore, $0<D^{o p t}<C F$ only if $r_{d}^{*}<k$ in this simple case.

$r_{X}$ depends on $X$ and $K_{1}^{c}$. The larger $X$ and the smaller $K_{1}^{c}$, the larger is $r_{X}$, the lower is the probability that the options will be in the money at $t=2$, the stronger will be the risk incentives from the option, and the more attractive will be internal (risky) investments as opposed to dividend payouts. Consequently, the optimal $r_{d}^{*}$ tends to be the higher, the larger $r_{X}$, and it follows (i) that the optimal dividend protection and the optimal exercice price cannot be determined independently, and (ii) that the optimal $r_{d}^{*}$ will be dependent on the stock price at $t=1$. Additionally, as the manager's compensation is expected to be the higher the higher is the stock price $K_{1}^{c}$ at $t=1$, dividend protection has to account for wealth effects. If wealth effects are present (due to the manager's non-constant absolute risk aversion), the stock price $K_{1}^{c}$ has an additional (indirect) effect on the manager's dividend decision and thus on the optimal $r_{d}^{*} \cdot 34$

\section{Stochastic interest rate $\tilde{\mathbf{r}}_{\mathrm{I}}^{*}$}

In case of a dividend protection with the stochastic interest rate $\widetilde{r}_{I}^{*}$ as defined in (13), the manager's expected utility $E[U(\widetilde{W})]$ is given by

$$
\begin{gathered}
E[U(\widetilde{W})]=\iint U(W) f\left(r_{I}\right) f(\varepsilon) d r_{I} d \varepsilon \quad \text { with } \\
\widetilde{W}=\alpha \cdot \max \left\{\left(K_{1 M}^{n}+\bar{\Delta}\right) \cdot(1+\widetilde{r})-\left[X-D\left(1+\widetilde{r}_{I}^{*}\right)\right] ; 0\right\} \quad \text { and }
\end{gathered}
$$

\footnotetext{
${ }^{33}$ Note that $\operatorname{Cov}\left[U^{\prime}(\widetilde{W}), \widetilde{r}\right]=E\left[\left(U^{\prime}(\widetilde{W})-E\left[U^{\prime}(\widetilde{W})\right) \cdot(\widetilde{r}-k)\right]=E\left[U^{\prime}(\widetilde{W}) \cdot \widetilde{r}\right]-E\left[U^{\prime}(\widetilde{W})\right] \cdot k\right.$. The general condition (A-3) (for any $r_{X}$ and $p_{M}$ ) can be written as $\hat{E}\left[U^{\prime}(\widetilde{W})\right] \cdot\left[1+r^{*}-\left(1+p_{M}\right) \frac{1+\hat{E}(\tilde{r})}{1+k}\right]-\frac{1+p_{M}}{1+k} \widehat{\operatorname{Cov}}\left[U^{\prime}(\widetilde{W}), \tilde{r}\right]=0$.

${ }^{34}$ As the manager can only decide about $D$ and therefore not about the allocation of his complete "budget", the results from the analysis of standard portfolio problems (see e.g. Merton (1982), pp 612-618) cannot be easily applied.
} 


$$
\widetilde{r}_{I}=i+\beta(\widetilde{m}-i)=\widetilde{r}-\widetilde{\varepsilon}
$$

In the following, assume that the options will almost surely be in the money at $t=2$, so that we can approximate the derivate with respect to $D$ by

$$
\frac{\partial E[U(\widetilde{W})]}{\partial D}=\iint U^{\prime}(W) \alpha\left[\frac{k-p_{M}}{1+k}\left(1+r_{I}\right)-\lambda-\frac{1+p_{M}}{1+k} \varepsilon\right] f\left(r_{I}\right) f(\varepsilon) d r_{I} d \varepsilon
$$

If $p_{M}=k$, it can be shown that there will only be an interior maximum for $D^{\text {opt }}$, $0<D^{o p t}<C F$, if $\lambda$ is strictly positive. As the agent's incentive to invest into firm specific risk $\tilde{\varepsilon}$ tends to be the larger, the larger is the probability that the options expire unexercised, this compensation $\lambda$ in $r_{I}^{*}$ tends to be the lower, the larger the risk incentive from the options' limited liability.

A comparison of dividend protection with a determinitic rate $r_{d}^{*}$ on the one hand and a stochastic rate $\tilde{r}_{I}^{*}$ on the other is difficult. For a preliminary analysis, let the dividend protection be designed such that, if $p_{M}=k, D^{o p t}=C F$ is an interior maximum for $E[U(\widetilde{W})]$ for both $r_{d}^{*}$ and $\tilde{r}_{I}^{*}$. Obviously, from the shareholders' perspective, the manager in either case tends to underinvest, since he would not reduce $D^{\text {opt }}$ to $D^{\text {opt }}=0$ if $p_{M}$ increased to a level $p_{M}>k$. Whether dividend protection based on $\tilde{r}_{I}^{*}$ is preferred to dividend protection based on $r_{d}^{*}$ now depends on how strongly $D^{\text {opt }}$ depends on $p_{M}$. Applying the implicit function theorem, we receive

$$
\left.\frac{d D}{d p_{M}}\right|_{\substack{D=C F \\ r^{*}=r_{d}^{*}}} ^{D=}=\frac{1}{\alpha(1+k)} \cdot \frac{E\left[U^{\prime}(\widetilde{W})(1+\widetilde{r})\right]}{E\left[U^{\prime \prime}(\widetilde{W})\left(\widetilde{r}-r_{d}^{*}\right)^{2}\right]}
$$

for dividend protection with $r_{d}^{*}$ and

$$
\left.\frac{d D}{d p_{M}}\right|_{\substack{D=C F \\ r^{*}=\tilde{r}_{I}^{*}}}=\frac{1}{\alpha(1+k)} \cdot \frac{E\left[U^{\prime}(\widetilde{W})(1+\widetilde{r})\right]}{E\left[U^{\prime \prime}(\widetilde{W})(\lambda+\tilde{\varepsilon})^{2}\right]}
$$

Both (A-7) and (A-8) are negative, i.e. the manager will reduce dividends if internal investments become more valuable - as is desired by the shareholders. Comparing (A-7) and (A-8) shows that they have structurally different denominators. ${ }^{35}$ The denominator of (A-7) includes the squared differences $\widetilde{r}-r_{d}^{*}=\widetilde{r}_{I}+\widetilde{\varepsilon}-r_{d}^{*}$, whereas the denominator

\footnotetext{
${ }^{35}(\mathrm{~A}-7)$ and (A-8) also differ with respect to the numerators, as the manager's wage $W$ is not identical in either case. Though, the absolute amount of this difference should be relatively small in comparison with the difference in the denominators.
} 
of (A-8) only includes the squared noise term $\widetilde{\varepsilon}$ (plus $\lambda$ ). Hence, the larger $\beta$ (i.e. the firm's systematic risk), the larger is the absolute value of the denominator of (A-7) compared to the absolute value of the denominator of $(\mathrm{A}-8)$ : the risk included in $\widetilde{r}_{I}^{*}$ but not in $r_{d}^{*}$ (and therefore filtered out by $\widetilde{r}_{I}^{*}$ but not by $r_{d}^{*}$ ) increases as $\beta$ gets larger. As a result, the manager tends to react more strongly to a change in $p_{M}$ if $\widetilde{r}_{I}^{*}$ is used for dividend protection instead of $r_{d}^{*}$. This relation still tends to hold if one relaxes the simplifying assumptions we made. So, in general, the manager's dividend decision will be more sensitive to $p_{M}$ and thus closer to the first best dividend policy if $\widetilde{r}_{I}^{*}$ is used for dividend protection instead of $r_{d}^{*}$. 


\section{Literature}

Arnold, Markus C. (2000): Ausgestaltungsformen für Aktienoptionsprogramme: Eine theoretische Betrachtung. Unpublished Master Thesis, University of Frankfurt.

Brander, James A./Poitevin, Michel (1992): Managerial Compensation and the Agency Costs of Debt Finance, Managerial and Decision Economics, 13, 55-64.

Carpenter, Jennifer (2000): Does Option Compensation Increase Managerial Risk Appetite?, Journal of Finance, 55, 2311-2332.

Comment, Robert/Jarrell, Gregg A. (1991): The Relative Signalling Power of Dutch-Auction and Fixed-Price Self-Tender Offers and Open-Market Share Repurchases, Journal of Finance, 46, 12431271.

Dann, Larry Y. (1981): Common Stock Repurchases: An Analysis of Returns to Bondholders and Stockholders, Journal of Financial Economics, 9, 113-138.

Dybvig, Philip H./Zender Jaime F. (1991): Capital Structure and Dividend Irrelevance with Asymmetric Information, Review of Financial Studies, 4, 201-219.

Fenn, George W./Liang, Nellie (2001): Corporate Payout Policy and Managerial Stock Incentives, Journal of Financial Economics, 60, 45-72.

Garvey, Gerald T./Mawani, Amin (1998): Executive Stock Options and the Mediation of StockholderBondholder Conflicts. Working Paper, Faculty of Commerce and Business Administration, University of British Columbia, Canada.

Hall, Brian J./Liebman, Jeffrey B. (1998): Are CEOs Really Paid Like Bureaucrats?, Quarterly Journal of Economics, 113, 653-691.

Hall, Brian J./Murphy, Kevin J. (2000a): Optimal Exercise Prices for Executive Stock Options, American Economic Review, 90, 209-215.

Hall, Brian J./Murphy, Kevin J. (2000b): Stock Options for Undiversified Executives, NBER-Working Paper No. 8052.

Ikenberry, David/Lakonishok, Josef/Vermaelen, Theo (1995): Market underreaction to open market share repurchases, Journal of Financial Economics, 39, 181-208.

John, Teresa A./John, Kose (1993): Top-Management Compensation and Capital Structure, Journal of Finance, 48, 949-974.

Jolls, Christine (1998): Stock Repurchases and Incentive Compensation, NBER Working Paper No. W6467.

Kahle, Kathleen M. (2002): When a Buyback isn't a Buyback: Open Market Repurchases and Employee Options, Journal of Financial Economics, 63, 235-261.

Klassen, Kenneth J./Sivakumar, Ranjini (2001): Stock Repurchases Associated with Stock Options Do Represent Dollars Out of Shareholders' Wallets, Working Paper, University of Waterloo.

Lambert, Richard/Lanen, William/Larcker, David (1989): Executive Stock Options Plans and Corporate Dividend Policy, Journal of Financial and Quantitative Analysis, 24, 409-425.

Lambert, Richard A./Larcker, David F./Verrecchia, Robert E. (1991): Portfolio Considerations in Valuing Executive Compensation, Journal of Accounting Research, 29, 129-149.

Liang, Nellie/Sharpe, Steven A. (1999): Share Repurchases and Employee Stock Options and their Implications for S\&P 500 Share Retirements and Expected Returns, Board of Governors of the Federal Reserve System Finance and Economics Working Paper No. 99-59.

Long, Michael S. (1992): The Incentives behind the Adoption of Executive Stock Option Plans in U.S. Corporations, Financial Management, 12-21. 
Menichetti, Marco (1996): Aktienoptionsprogramme für das Top-Management, Der Betrieb, 49, 16881692 .

Merton, Robert C. (1982): On the Microeconomic Theory of Investment under Uncertainty, Handbook of Mathematical Economics, II, K.J. Arrow und M.D. Intrilligator (eds.), 601-669.

Meulbroek, Lisa M. (2001): The Efficiency of Equity-Linked Compensation: Understanding the Full Cost of Awarding Executive Stock Options, Financial Management, 30, 5-44.

Murphy, Kevin J. (1999): Executive Compensation, Handbook of Labour Economics, Orley Ashenfelder/David Card (eds.), 3.

Myers, Stewart C./Majluf Nicholas S. (1984): Corporate Financing and Investment Decisions when Firms have Information that Investors do not have, Journal of Financial Economics, 13, 187-221.

Neus, Werner (1996): Realinvestitionen, Finanzinvestitionen und Anreizverträge, Zeitschrift für Betriebswirtschaft, $66,1127-1147$.

Otchere, Isaac K./Ross, Matthew (2001): Do Share Buy Back Announcements Convey Firm Specific or Industry-wide Information? A Test of the Undervaluation Hypothesis, International Review of Financial Analysis, Forthcoming.

Persons, John C. (1994): Renegotiation and the Impossibility of Optimal Investment, Review of Financial Studies, 7, 419-449.

Rappaport, Alfred (1999): New Thinking on how to Link Executive Pay with Performance, Harvard Business Review, 91-101.

Schwetzler, Bernhard (1999): Shareholder Value Konzept, Managementanreize und Stock Option Plans, Die Betriebswirtschaft, 59, 332-350.

Vermaelen, Theo (1981): Common Stock Repurchases and Market Signalling: An Empirical Study, Journal of Financial Economics, 9, 139-183.

Vermaelen, Theo (1984): Repurchase Tender Offers, Signaling, and Managerial Incentives, Journal of Financial and Quantitative Analysis, 19, 163-181.

Weisbenner, Scott J. (2000): Corporate Share Repurchases in the 1990s: What Role Do Stock Options Play?, FEDS Working Paper No. 2000-29.

Wenger, Ekkehard/Kaserer, Christoph/Knoll, Leonard (1999): Stock Options - Manageranreize zwischen Anspruch und Realität, Managementinstrumente und -konzepte, A. Egger/O. Grün/R. Moser (eds.), 481-509.

Winter, Stefan (2000): Optionspläne als Instrument wertorientierter Managementvergütung, Frankfurt/Main et.al. 